\title{
Actinomyces neuii: a case report of a rare cause of acute infective endocarditis and literature review
}

\author{
Wei-Teng Yang ${ }^{1 *}$ (D) and Matthew Grant ${ }^{2}$
}

\begin{abstract}
Background: Infective endocarditis caused by Actinomyces spp. is extremely rare. However, cases by new species of Actinomyces have been increasingly reported due to advances in laboratory techniques, and many of these species do not cause classic presentations of actinomycosis. Actinomyces neuii is reported to have a tendency to cause endovascular infection. The course of infective endocarditis caused by Actinomyces spp. is usually indolent.

Case presentation: A 61-year-old man with history of infective endocarditis, end stage renal disease, and monoclonal gammopathy was admitted for an abrupt fever, confusion, dysarthria, and facial droop after hemodialysis. Echocardiogram showed vegetations on both the aortic and mitral valves. Two sets of blood culture grew A. neuii. Brain MRI showed multiple bilateral cerebral infarcts consistent with septic emboli. The patient recovered after valvular surgery and prolonged intravenous and oral antibiotic therapy.

Conclusions: This case illustrates an unusually acute presentation of A. neuii infective endocarditis. As with other Gram-positive bacilli, Actinomyces spp. isolates are often regarded as a result of contamination. One should keep it in mind as a cause of infective endocarditis in vulnerable patient populations.
\end{abstract}

Keywords: Actinomyces neuii, Actinomyces, Infective endocarditis

\section{Background}

Actinomyces spp. classically cause human actinomycosis, an indolent granulomatous infectious disease characterized by orocervicofacial, thoracic, abdominopelvic, or central nervous system abscess formation and draining sinuses [1]. Many novel Actinomyces species have been reported in recent decades with the advance in laboratory identification methods, and are associated with a wide range of infection at many body sites [2]. However, infective endocarditis by Actinomyces spp. is still extremely rare. We report a patient who presented with an acute Actinomyces neuii (A. neuii) aortic and mitral valve endocarditis complicated by aortic root abscess and septic cerebral emboli. He was treated successfully with surgery and prolonged antibiotics. We then present a review of published Actinomyces spp. endocarditis cases following a systematic literature search.

\footnotetext{
* Correspondence: Wei-Teng.Yang@ynhh.org

'Department of Internal Medicine, Yale New Haven Health Bridgeport

Hospital, 267 Grant Street, Bridgeport, CT 06610, USA

Full list of author information is available at the end of the article
}

\section{Case presentation}

Clinical presentation and diagnostic findings

A 61 year-old man was admitted with a $103^{\circ} \mathrm{F}$ fever, confusion, weakness and slurred speech after hemodialysis. He had a history of viridans streptococcal mitral valve endocarditis, end stage renal disease on hemodialysis, atrial fibrillation not on anticoagulation due to GI bleeding, and monoclonal gammopathy of undetermined significance. He had a productive cough for a week without any identifiable sick contact. Physical examination was notable for an agitated edentulous man with a left central facial palsy, severe dysarthria, and a systolic murmur at the left lower sternal border. His lungs were clear to auscultation and there was no stigmata of endocarditis.

The patient was initially treated empirically for pneumonia and worked up for stroke. However, the treatment plan was quickly modified when a transthoracic echocardiogram on day two of admission revealed two echogenic structures consistent with vegetations: $0.4 \times$ $0.4 \mathrm{~cm}$ on the anterior leaflet of the mitral valve, and the other $0.7 \times 1.8 \mathrm{~cm}$ attached to left coronary cusp of the

(c) The Author(s). 2019 Open Access This article is distributed under the terms of the Creative Commons Attribution 4.0 International License (http://creativecommons.org/licenses/by/4.0/), which permits unrestricted use, distribution, and 
aortic valve (Fig. 1). There was also thickening of the aortic root suggestive of abscess formation. Two sets of blood culture grew Gram-positive rods after $37.5 \mathrm{~h}$ incubating in anaerobic bottles (Fig. 2), and after $86 \mathrm{~h}$ in aerobic bottles. The organism was identified as $A$. neuii by MALDI-TOF MS on day five of admission. Serial brain MRI scans revealed multiple bilateral infarcts on day two with increased number of infarcts and a small focus of hemorrhage on day five. The patient was diagnosed with infective endocarditis by $A$. neuii complicated by aortic root abscess and presumed cerebral septic emboli.

\section{Treatment and outcome}

The patient was initially treated with vancomyin and piperacillin/tazobactam until $A$. neuii was identified. Subsequently, he was treated with ampicillin and gentamicin for two days, followed by ampicillin for the rest of his hospitalization. The choice of ampicillin was based on a large series that studied susceptibility to antibiotics of Actinomyces species [3], and a previously successfully treated A. neuii endocarditis case [4]. Antibiotic susceptibility was not tested for our patient because he responded to the treatment well, and repeat blood cultures were all negative. A CT angiography of the brain and neck on day six ruled out mycotic aneurysm. It was concluded that the risk of further septic embolization outweighed the risk of intracranial hemorrhage, and the patient underwent aortic valve replacement, debridement of aortic root subannular abscess, mitral valve repair, and repair of a fistula between the aorta and left atrium on hospital day fourteen. A $2.5 \times$ $0.6 \mathrm{~cm}$ vegetation on the aortic valve and a vegetation on the mitral chordae tendineae were removed. There was no microscopic evidence of bacterial elements on the aortic valve based on histopathology with Gram stain, and culture did not grow any organisms. The patient's postoperative course was complicated by shock requiring intraaortic balloon pump, and a cardiac arrest from ventricular fibrillation 10 days after surgery. He recovered without further neurological deterioration, and was discharged to a nursing facility two months after heart surgery. He received 12 weeks of IV ampicillin followed by 11 months of oral doxycycline.

One year after the diagnosis of A. neuii endocarditis, while on chronic doxycycline, the patient had a fever and a bacteremia with coagulase negative Staphylococcus and group B Streptococcus. The bacteremia was sterilized after the initiation of antibiotic therapy and there was no growth from subsequent blood cultures. Transthoracic echocardiogram showed a small, mobile echogenic density on the non-coronary cusp of the bioprosthetic aortic valve. The patient refused to undergo transesophageal echocardiogram to further evaluate the prosthetic valve, so he was treated empirically for possible prosthetic valve endocarditis. The patient was cured from infection after two weeks of IV vancomycin and gentamicin, followed by four weeks of IV vancomycin. He had been taking oral doxycycline in addition to his IV antibiotics.

The patient eventually died of a sudden cardiac arrest after hemodialysis. This was 15 months after the diagnosis of A. neuii infective endocarditis, and four weeks after discontinuation of oral doxycycline. The family declined autopsy.

\section{Literature review}

Primary infective endocarditis caused by Actinomyces spp. is rare. After PubMed (search term ((actinomyces spp) OR actinomyces) AND ((infective endocarditis) OR endocarditis)) and additional bibliographical search, we found 26 human cases dating back to 1939 (Table 1), after excluding four reports, two with bacteria that have been subsequently reclassified to different genera [29, 30], one report with possible direct extension of pulmonary actinomycosis to the endocardium [31], and one with primary IUD-associated actinomyosis and secondary endocarditis [32]. Cases were reported at all ages (687 years old). Two thirds of patients were men. The

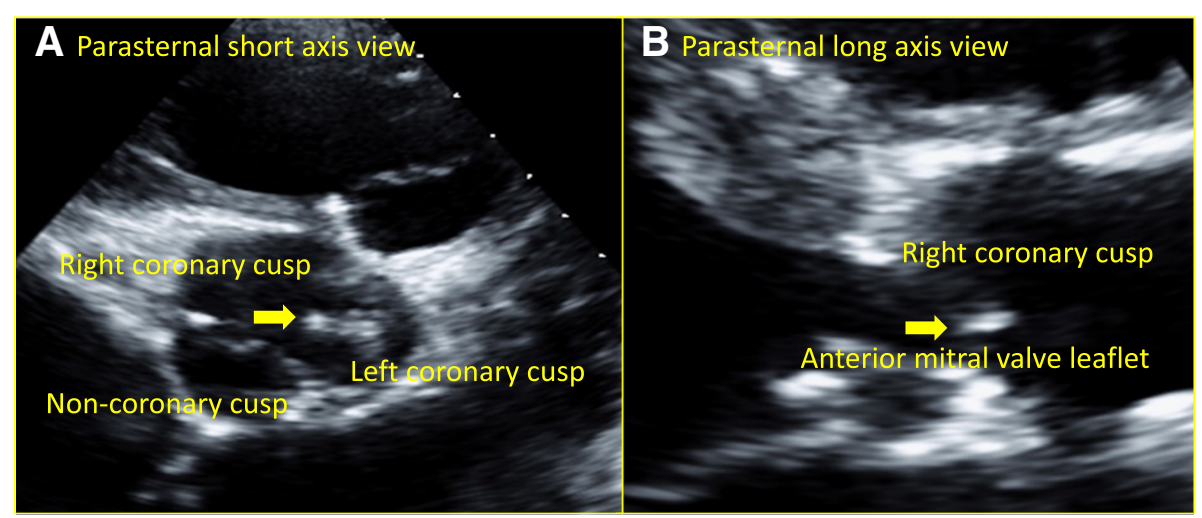

Fig. 1 Transthoracic echocardiogram showed two vegetations on the aortic and mitral valves. Legend: Vegetations on the aortic valve (panel a) and the mitral valve (panel b) were pointed by arrows 


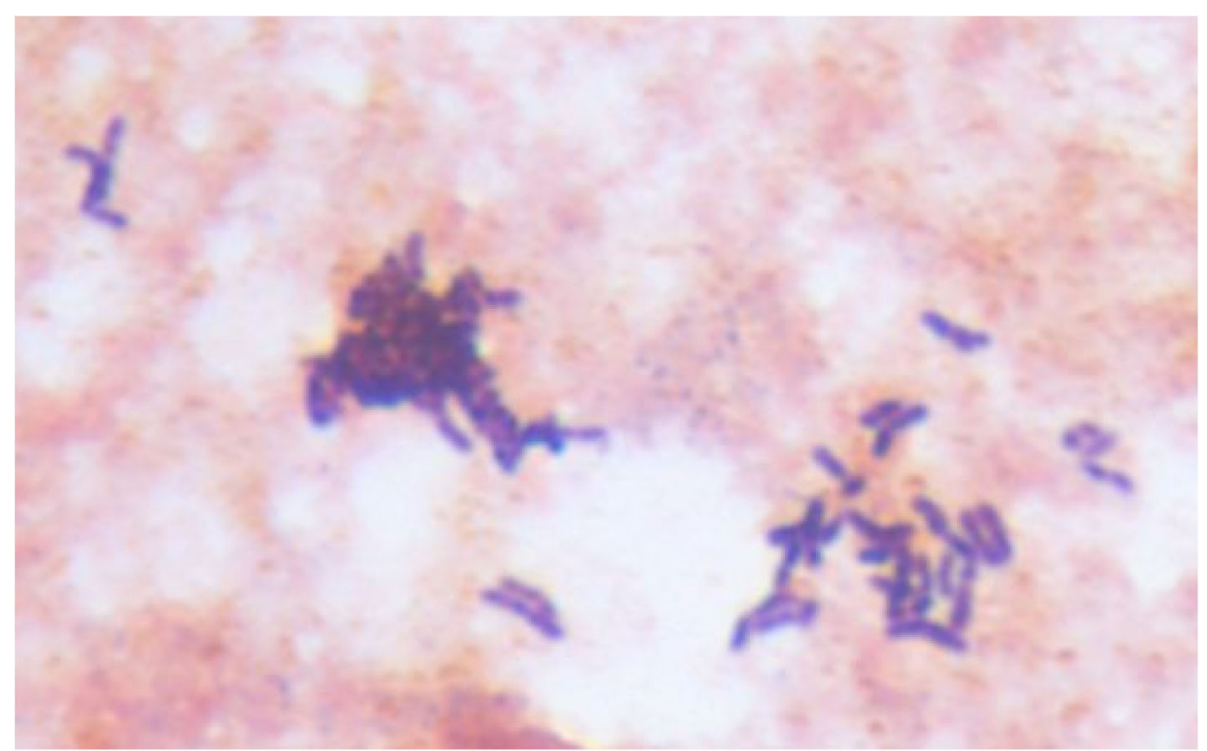

Fig. 2 Gram stain morphology of A. neuii bacteria. Legend: A. neuii bacteria were shown as small, Gram- positive rods. They are non-filamentous and do not produce sulfur granules seen commonly with other Actinomyces species

most commonly identified species were A. israelii (19\%) and $A$. viscosus (15\%). Twenty-two cases involved leftsided valves (mitral 9; aortic 5; prosthetic aortic 3; both mitral and aortic 4; undetermined 1). Risk factors included valvular disease (41\%), poor dental hygiene or dental procedure (36\%), and prosthesis (14\%). All four right-sided cases were associated with intravenous drug use $[17,19,22,25]$.

Most left-sided endocarditis patients had indolent courses. This did not seem to vary over time. However, the mortality and complications have improved significantly over time. Five of eight patients reported before 1990 died and five had embolic events (brain, spleen, kidneys, small bowel and skin), whereas only two of 14 cases reported after 1990 died, and only one had emboli to skin. Despite temporal courses of a subacute endocarditis, where stigmata of endocarditis are more common, only one report described Roth's spots [27]. It is unclear whether this was related to virulence factors from Actinomyces spp., or simply the rarity of these complications [33]. Right-sided endocarditis cases had more acute and fulminant courses, and were all complicated by septic emboli to the lungs. Two (50\%) of them had polymicrobial endocarditis [19, 25], which might have contributed to more complicated clinical courses. All four rightsides cases survived and all were reported after the year of 2000. Irrespective of the side of endocarditis, most patients were treated with a prolonged course of penicillin or $\beta$-lactam antibiotics. Four cases had surgery (three aortic valves $[4,13,18]$ and one Eustachian valve [22], an embryologic remnant of the valve of the inferior vena cava).
Two cases of infective endocarditis by $A$. neuii were previously reported $[4,24]$. Both were in older men with preexisting aortic valvular anomalies (one had a bicuspid valve and the other a prosthetic valve). Both presented with subacute endocarditis, large aortic vegetations $(2 \mathrm{~cm})$ and root abscesses. The patient with a native valve underwent surgery [4]. Both patients were cured from the infection. One was initially treated with ampicillin, then ceftriaxone due to interstitial nephritis, and finally doxycycline for 9 months [4]. The other was treated with penicillin, followed by amoxicillin for 12 months [24].

\section{Discussion and conclusion}

Infections caused by Actinomyces species, including classic actinomycosis and a range of other infections, usually have indolent courses and favorable outcomes [2]. This pattern was also supported by our review of endocarditis patients. Actinomyces species are also very susceptible to antibiotics, except for metronidazole [3, 34]. Such susceptibility to antibiotics, along with advances in diagnosis and management of infective endocarditis, likely contributed to the temporal drop of mortality and systemic complication rates observed from our literature review. Therefore, it was unexpected for our patient to present with an acute course and severe complications. Little is known about the virulence properties of Actinomyces spp. [2], but we hypothesize that the valvular damage from previous endocarditis and relative immune deficiency from his end stage renal disease and monoclonal gammopathy may have weakened our patient's host defense mechanism, and consequently led to a 


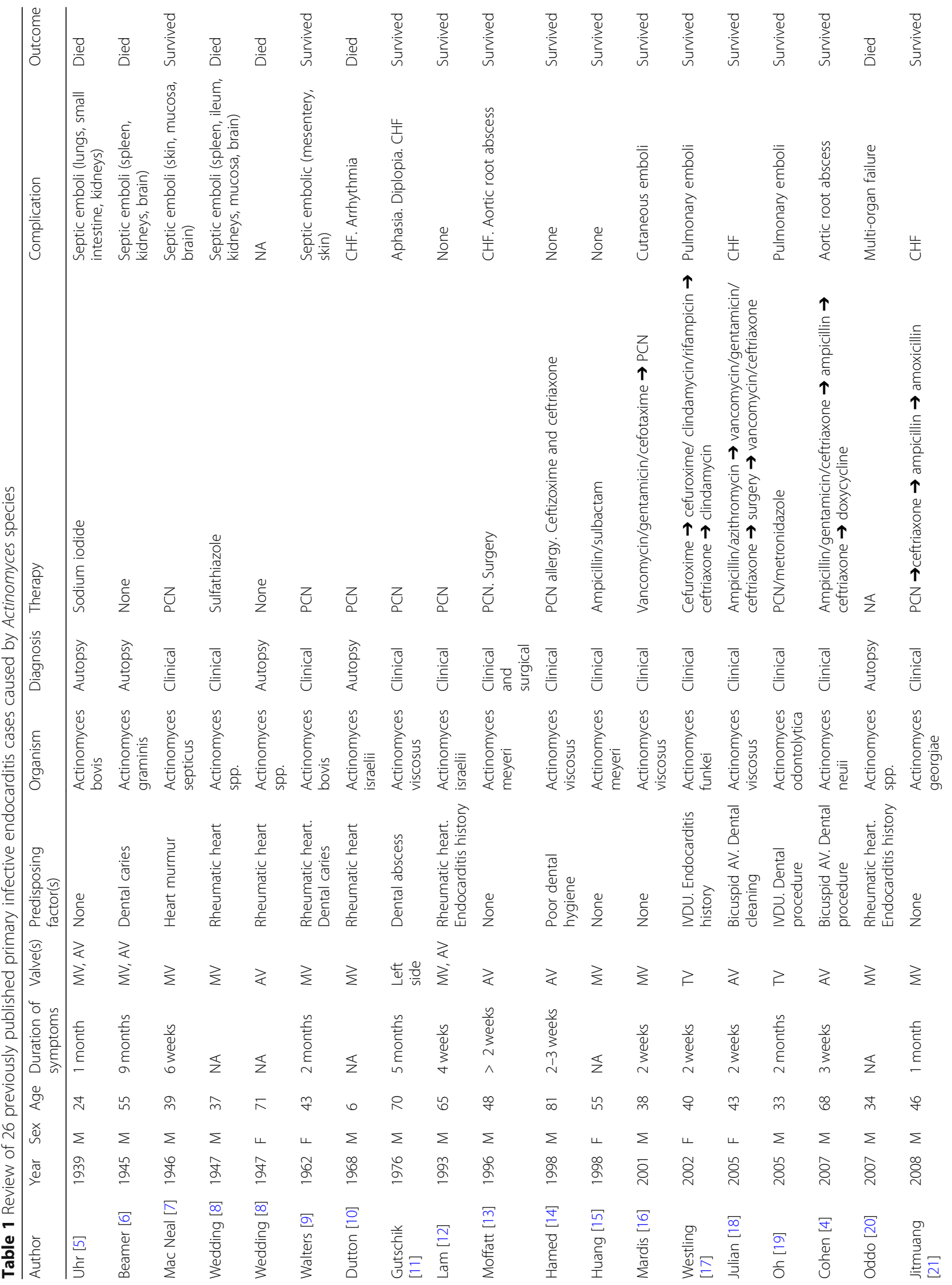




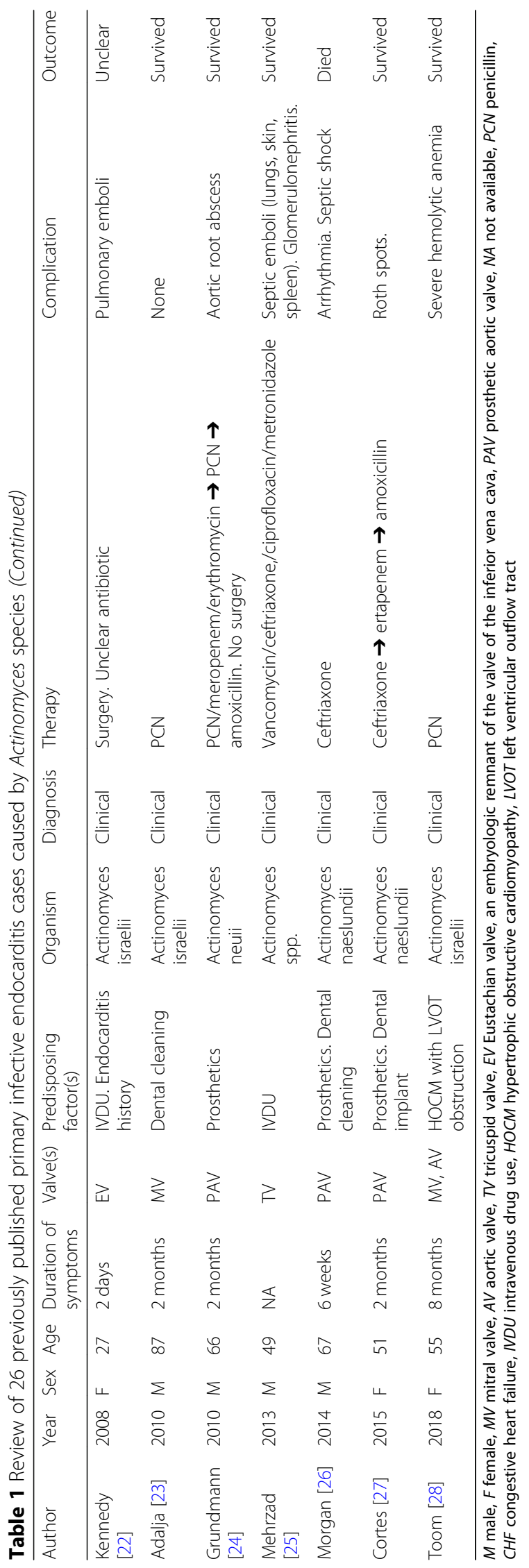


more fulminant course from a pathogen of lower virulence.

A. neuii was classified to the genus of Actinomyces in 1994. It is a small, non-filamentous rod that does not produce sulfur granules commonly seen in other Actinomyces species. Unlike most Actinomyces spp. that are anaerobic or at best aerotolerant organisms, A. neuii grows in both anaerobically and aerobically incubated samples [35]. It was the third most common diphtheroid and the most common Actinomyces species isolated from a tertiary center [36]. It has been reported in infected atheromas [37], abscesses [37], infected foreign bodies [2], urine [36] and endophthalmitis [38, 39]. There have been only a few case reports of classic actinomycosis caused by $A$. neuii. Notably they were all related to breast infections [40-44]. The infection caused by it is thought to be endogenous [35]. The affinity of $A$. neuii to atheromas was only reported in one of the earliest reports, and how infections in atheromas were determined is unclear [37]. However, with such propensity to endovascular infection, it is possible that frequent cannulation for hemodialysis might have contributed to our patient's infection by $A$. neuii. The outcomes from infections by $A$. neuii are favorable [45]. Given the paucity of cases, our antibiotic selection was based on a previously successfully treated A. neuii endocarditis case [4]. The evaluation of neurological complications, and the timing of surgery were challenging, but our management was in line with the latest surgical guideline [46]. The patient's subsequent possible prosthetic valve endocarditis and eventual death likely reflected his overall poor prognosis, rather than recurrent $A$. neuii endocarditis.

Gram-positive rods, "diphtheroid" or "coryneform", are often disregarded as contaminants from skin or mucosal surfaces, but $20 \%$ of diphtheroid isolates were found to cause clinically significant infections in a large study [36]. Actinomyces spp. are among these Grampositive rods, and their identification in clinical microbiology laboratories can be challenging [2, 47]. As such, delayed diagnoses are common [13, 18, 23], and it is thought endocarditis by Actinomyces spp. is underestimated and Actinomyces spp. are likely a cause of culture negative endocarditis. Advances in laboratory methods, primarily MALDI-TOF MS, are correctly and increasingly identifying Actinomyces spp. from clinical samples. Clinicians should carefully evaluate the relevance of an Actinomyces spp. isolate before disregarding it, especially in a vulnerable patient like ours, and in a species that is associated with endovascular infection like $A$. neuii.

To conclude, we reported a successfully treated acute infective endocarditis case with severe complications by A. neuii, a rare but increasingly clinically relevant Actinomyces species associated with endovascular infection. Our review showed Actinomyces spp. infective endocarditis is usually indolent and responds favorably to treatment. Clinicians should carefully evaluate the relevance of Actinomyces spp. in infections to avoid delayed or missed diagnoses.

\section{Abbreviations}

CT: Computed tomography; Gl: Gastrointestinal; IUD: Intrauterine device; IV: Intravenous; MALDI-TOF MS: Matrix-assisted laser desorption ionization time-of-flight mass spectrometry; MRI: Magnetic resonance imaging

\section{Acknowledgements}

Not applicable.

\section{Authors' contributions}

WTY attended to the patient, did the literature review, and wrote the case report. MG provided pictures of echocardiography and was responsible for reviewing and revising the manuscript. Both authors have read the manuscript and accepted the final version.

\section{Funding}

Not applicable.

Availability of data and materials

Not applicable. No datasets were generated for this study.

Ethics approval and consent to participate

Not applicable.

\section{Consent for publication}

WTY personally obtained a written consent from the patient before his demise. The patient was made aware of the fact that his anonymity cannot be fully guaranteed and that there is a possibility that he could be identified based on the case report information and/or clinical images.

\section{Competing interests}

The authors declare that they have no competing interest.

\section{Author details}

${ }^{1}$ Department of Internal Medicine, Yale New Haven Health Bridgeport Hospital, 267 Grant Street, Bridgeport, CT 06610, USA. ²Department of Internal Medicine, Section of Infectious Diseases, Yale School of Medicine, PO Box 208022, New Haven, CT 06510, USA.

Received: 2 April 2019 Accepted: 31 May 2019

Published online: 10 June 2019

\section{References}

1. Smego RA Jr, Foglia G. Actinomycosis. Clin Infect Dis. 1998;26(6):1255-61.

2. Kononen E, Wade WG. Actinomyces and related organisms in human infections. Clin Microbiol Rev. 2015;28(2):419-42.

3. Hansen JM, Fjeldsoe-Nielsen H, Sulim S, Kemp M, Christensen JJ. Actinomyces species: a danish survey on human infections and microbiological characteristics. Open Microbiol J. 2009;3:113-20.

4. Cohen E, Bishara J, Medalion B, Sagie A, Garty M. Infective endocarditis due to Actinomyces neuii. Scand J Infect Dis. 2007;39(2):180-3.

5. Uhr N. Bacterial endocarditis: report of a case in which the cause was Actinomyces bovis. Arch Intern Med. 1939:64(1):84-90.

6. Beamer PR, Reinhard EH. Goodof II: Vegetative endocarditis caused by higher bacteria and fungi: Review of previous cases and report of two cases with autopsies. Am Heart J. 1945;29(1):99-112.

7. Mac Neal WJ, Blevins A, Duryee AW. Clinical arrest of endocardial actionomycosis after forty-four million units of penicillin. Am Heart J. 1946; 31(6):668-76.

8. Wedding ES. Actinomycotic endocarditis: report of two cases with a review of the literature. Arch Intern Med. 1947;79(2):203-27.

9. Walters EW, Eomansky MJ, Johnson AC, Conway SJ. Actinomyces bovis endocarditis: an uncommon and complex problem. Antimicrob Agents Chemother (Bethesda). 1962:2(5):517-25.

10. Dutton WP, Inclan AP. Cardiac actinomycosis. Chest. 1968;54(5):463-5. 
11. Gutschik E. Endocarditis caused by Actinomyces viscosus. Scand J Infect Dis. 1976;8(4):271-4.

12. Lam S, Samraj J, Rahman S, Hilton E. Primary actinomycotic endocarditis: case report and review. Clin Infect Dis. 1993;16(4):481-5.

13. Moffatt S, Ahmen AR, Forward K. First reported case of bacterial endocarditis attributable to Actinomyces meyeri. Can J Infect Dis. 1996; 7(1):71-3.

14. Hamed KA. Successful treatment of primary Actinomyces viscosus endocarditis with third-generation cephalosporins. Clin Infect Dis. 1998; 26(1):211-2.

15. Huang KL, Beutler SM, Wang C. Endocarditis due to Actinomyces meyeri. Clin Infect Dis. 1998;27(4):909-10.

16. Mardis JS, Many WJ Jr. Endocarditis due to Actinomyces viscosus. South Med J. 2001;94(2):240-3.

17. Westling K, Lidman C, Thalme A. Tricuspid valve endocarditis caused by a new species of actinomyces: Actinomyces funkei. Scand J Infect Dis. 2002; 34(3):206-7.

18. Julian $K G$, de Flesco L, Clarke LE, Parent LJ. Actinomyces viscosus endocarditis requiring aortic valve replacement. J Inf Secur. 2005;50(4): 359-62.

19. Oh S, Havlen PR, Hussain N. A case of polymicrobial endocarditis caused by anaerobic organisms in an injection drug user. J Gen Intern Med. 2005; 20(10):C1-2.

20. Oddó BD, Ayala RF. Endocarditis infecciosa actinomicótica de la válvula mitral: Caso de autopsia y revisión de la literatura. Rev Chil Infectol. 2007;24:232-5.

21. Jitmuang A. Primary actinomycotic endocarditis: a case report and literature review. J Med Assoc Thail. 2008;91(6):931-6.

22. Kennedy JL, Chua DC, Brix WK, Dent JM. Actinomycotic endocarditis of the eustachian valve. Echocardiography. 2008;25(5):540-2.

23. Adalja AA, Vergis EN. Actinomyces israelii endocarditis misidentified as "diptheroids". Anaerobe. 2010;16(4):472-3.

24. Grundmann S, Huebner J, Stuplich J, Koch A, Wu K, Geibel-Zehender A, Bode C, Brunner M. Prosthetic valve endocarditis due to Actinomyces neuii successfully treated with antibiotic therapy. J Clin Microbiol. 2010;48(3): 1008-11.

25. Mehrzad R, Sublette M, Barza M. Polymicrobial endocarditis in intravenous heroin and fentanyl abuse. J Clin Diagn Res. 2013;7(12):2981-5.

26. Morgan LG, Davis AL, Poommipanit P, Ahmed Y. Actinomyces naeslundii, a previously undocumented cause of infective endocarditis; with literary review. Am J Infect Dis. 2014;10(3):132-6.

27. Cortes CD, Urban C, Turett G. Actinomyces naeslundii: an uncommon cause of endocarditis. Case Rep Infect Dis. 2015;2015:602462.

28. Toom S, Xu Y. Hemolytic anemia due to native valve subacute endocarditis with Actinomyces israelii infection. Clin Case Rep. 2018;6(2):376-9.

29. Reddy I, Ferguson DA Jr, Sarubbi FA. Endocarditis due to Actinomyces pyogenes. Clin Infect Dis. 1997;25(6):1476-7.

30. Stokes JF, Gray IR, Stokes EJ. Actinomyces muris endocarditis treated with chloramphenicol. Br Heart J. 1951;13(2):247-51.

31. O'Sullivan RA, Armstrong JG, Rivers JT, Mitchell CA. Pulmonary actinomycosis complicated by effusive constrictive pericarditis. Aust NZ J Med. 1991;21(6):879-80.

32. Kottam A, Kaur R, Bhandare D, Zmily H, Bheemreddy S, Brar H, Herawi M, Afonso $\mathrm{L}$. Actinomycotic endocarditis of the eustachian valve: a rare case and a review of the literature. Tex Heart Inst J. 2015:42(1):44-9.

33. Wang A, Gaca JG, Chu VH. Management considerations in infective endocarditis: a review. JAMA. 2018:320(1):72-83.

34. Steininger $C$, Willinger $B$. Resistance patterns in clinical isolates of pathogenic Actinomyces species. J Antimicrob Chemother. 2016;71(2): 422-7.

35. von Graevenitz A. Actinomyces neuii: review of an unusual infectious agent. Infection. 2011;39(2):97-100.

36. Leal SM Jr, Jones M, Gilligan PH. Clinical significance of commensal grampositive rods routinely isolated from patient samples. J Clin Microbiol. 2016; 54(12):2928-36.

37. Funke G, von Graevenitz A. Infections due to Actinomyces neuii (former "CDC coryneform group 1" bacteria). Infection. 1995:23(2):73-5.

38. Sahni S, Watson RM, Sheth VS. Actinomyces neuii endophthalmitis after intravitreal anti-vascular endothelial growth factor injection. Retin Cases Brief Rep. 2017;11(3):281-2
39. Raman VS, Evans N, Shreshta B, Cunningham R. Chronic postoperative endophthalmitis caused by Actinomyces neuii. J Cataract Refract Surg. 2004 30(12):2641-3.

40. Lacoste C, Escande MC, Jammet P, Nos C. Breast Actinomyces neuii abscess simulating primary malignancy: a case diagnosed by fine-needle aspiration. Diagn Cytopathol. 2009;37(4):311-2

41. Leenstra BS, Schaap CCM, Bessems M, Renders NHM, Bosscha K. Primary actinomycosis in the breast caused by Actinomyces neuii. A report of 2 cases. IDCases. 2017;8:70-2.

42. Mahendiran SA, Leibman AJ, Kommehl AS. Male breast abscess secondary to actinomycosis: a case report. J Clin Diagn Res. 2016;10(4):TD05-7.

43. Olson JM, Vary JC Jr. Primary cutaneous Actinomyces neuii infection of the breast successfully treated with doxycycline. Cutis. 2013;92(6):E3-4.

44. Roustan A, Al Nakib M, Boubli L. Primary actinomycosis of the breast due to Actinomyces neuii. J Gynecol Obstet Biol Reprod (Paris). 2010;39(1):64-7.

45. Zelyas N, Gee S, Nilsson B, Bennett T, Rennie R. Infections caused by Actinomyces neuii: a case series and review of an unusual bacterium. Can J Infect Dis Med Microbiol. 2016;2016:6017605.

46. Pettersson GB, Coselli JS, Hussain ST, Griffin B, Blackstone EH, Gordon SM, LeMaire SA, Woc-Colburn LE. 2016 the American Association for Thoracic Surgery (AATS) consensus guidelines: surgical treatment of infective endocarditis. J Thorac Cardiovasc Surg. 2017:153(6):1241-58 e1229.

47. Wong VK, Turmezei TD, Weston VC. Actinomycosis. BMJ. 2011;343:d6099.

\section{Publisher's Note}

Springer Nature remains neutral with regard to jurisdictional claims in published maps and institutional affiliations.
Ready to submit your research? Choose BMC and benefit from:

- fast, convenient online submission

- thorough peer review by experienced researchers in your field

- rapid publication on acceptance

- support for research data, including large and complex data types

- gold Open Access which fosters wider collaboration and increased citations

- maximum visibility for your research: over $100 \mathrm{M}$ website views per year

At $\mathrm{BMC}$, research is always in progress.

Learn more biomedcentral.com/submissions 